\title{
Validity of smokers' information about present and past cigarette brands - implications for studies of the effects of falling tar yields of cigarettes on health
}

\author{
HEDLEY PEACH, D SHAH, RW MORRIS \\ From the Department of Community Medicine, United Medical and Dental Schools of Guy's and St Thomas's \\ Hospitals, London
}

ABSTRACT Four hundred and twenty nine current smokers and ex-smokers who had provided details 12 years previously completed a self administered questionnaire about their present and past smoking habits, and two weeks later current smokers supplied an empty cigarette packet. The tar group and brand name of the current cigarette given on the questionnaire were compared with details on the packet, and the brand alleged to have been smoked 12 years ago was compared with that actually recorded at that time. Only 55\% of "low middle" tar cigarettes as indicated by returned packets had been correctly identified in the questionnaire. The brand name was the same in the questionnaire and on the packet in $74 \%$ of cases. The recalled brand was confirmed by past records in only $49 \%$ of cases. It is concluded that current smokers should be asked to return an empty packet or packets of the cigarette brand or brands usually smoked with a self administered questionnaire and that follow up studies of populations for which brands of cigarette smoked were previously recorded might be more valid.than studies relying on recall.

Several studies have attempted to establish whether there is any benefit to cigarette smokers in changing from a higher to a lower tar brand. Most of these are cross sectional, ${ }^{1-6}$ prospective, ${ }^{7-12}$ or retrospective $^{13-16}$ studies in which information about cigarette type and brand, present or past or both, had to be obtained from smokers themselves. None of these studies tested the validity of smokers' answers about past and present cigarette type and brand. This is surprising, not only because of the fundamental nature of the information but also because the Tobacco Research Council showed 20 years ago that the proportion of smokers of manufactured and hand rolled cigarettes incorrectly recalling even the type of cigarette (manufactured or hand rolled) they had smoked increased from an average of $8 \%$ one and a half years after the initial interview to $35 \%$ at 15 years. ${ }^{17}$ Recall of the actual brand name of cigarettes smoked in the past is likely to be even poorer. Retrospective studies trying to assess the effects of switch-

Address for correspondence: Mr RW Morris, Department of Community Medicine, St Thomas's Hospital Medical School, London SE1 7EH.

Accepted 23 September 1985 ing brands on health may have to collect information on brands on the basis of recall over a long period because of the time taken for some effects to become apparent. For example, Fletcher et al $^{18}$ showed that at least eight years of follow up is needed to distinguish even between smokers and ex-smokers on the basis of lung function tests. Moreover, the validity of information about current cigarettes smoked (type, tar group, or brand name) has never been established, for example, against the details on the packet.

In this paper we assess the validity of smokers' information about present and past cigarette brands and discuss the implications of the results for past and future studies of the effects of the falling tar yields of cigarettes on health.

\section{Method}

The Heart Disease Prevention Project was a randomised controlled trial of the benefits to middle aged men of mounting a preventive campaign in industry. ${ }^{19}$ At the start of the study in 1971-3 a self administered questionnaire was used to obtain data on the type and brand of cigarette smoked from all men employed in the 12 intervention factories and $10 \%$ of those in the 12 control factories. The men were asked 
whether they smoked manufactured cigarettes with filters, manufactured cigarettes without filters, or hand rolled cigarettes and were required to state precisely the brand of cigarette or tobacco usually smoked.

Ten factories, five intervention and five control, which had not been closed and had not had many redundancies, were chosen for this study. At the start of the Heart Disease Prevention Project these factories had 8743 male workers aged 40-59 years. Of the men who were still contactable at the last follow up of the project in 1977-8 (62\%), a random sample of 1204, stratified according to whether they were retired, were sent a self administered questionnaire in 1984. This inquired about the type (plain, filter, or hand rolled), tar group ("high," "middle high," "middle," "low middle," "low," "not known"), brand name, and the number of years they had smoked their usual present cigarettes and the brand of cigarettes they thought they had been smoking at the start of the project.

The respondents were asked to give the brand names as fully as possible and to include any words such as "King Size," letters as in "Craven A," or numbers as in "State Express 555" written on the front, back, or sides of the cigarette packet. The present cigarette brands were coded by one observer using a dictionary of brands on the market since 1978 (PN Lee, personal communication), to which hand rolled tobaccos were added. If the brand information in the questionnaire could not be matched with only one cigarette described in the dictionary then the questionnaire data were recorded as uncodable. For example,

Questionnaire brand:

Player's No 6

Dictionary brands:

309 Player's No 6 Filter

101 Player's No 6 Plain

S F 1965-

310 Player's No 6 Extra Mild Filter S F 1972-

618 Player's No 6 King Size Filter KS F 1971-

(S-small; KS-King Size; F-filter; P-plain)

Decision: uncodable

The recalled brands from 12 years ago were coded according to the original coding frame of the
Heart Disease Prevention Project (appendix). This coding frame may produce an overestimate of the agreement between recalled and actual brands smoked at the start of the project since the precise Embassy cigarette, for example, smoked 12 years ago cannot be identified.

Two weeks after returning their questionnaires smokers were asked to send an empty packet of the cigarette or hand rolled tobacco usually smoked. The type, tar group, and brand name of the usual cigarette given on the questionnaire were compared with the details on the packet. Smokers who returned a packet carrying a brand name or tar group that did not agree with those given on the questionnaire were asked by letter or telephone whether they had changed brands since completing the questionnaire. The questionnaire inquired about the length of time that the men had been smoking their cigarette brands and we could therefore check whether the brands cited were likely to be the smoker's usual brands. The brand alleged to have been smoked 12 years ago was also compared with that actually recorded at the start of the project.

\section{Results}

The response rate to the questionnaire after three mailings was $83 \%$. Intervention and control factory workers were similar with respect to response, social class, and smoking habits 12 years previously. The respondents from the five intervention factories, however, were slightly older (60.7 compared with 59.7 years; $p<0.05$ ). Non-respondents were similar to respondents in age, social class, and smoking habits 12 years before. Workers from the 10 factories surveyed in this study were also compared with the original 24 factory populations with respect to their characteristics on entry. Smoking was slightly less common in the 10 chosen factories than in the remaining 14 . The ages of the two populations were similar.

Four hundred and twenty nine men who returned a questionnaire smoked cigarettes at the start of the Heart Disease Prevention Project. Of these, 243 still smoked cigarettes and all but 23 forwarded a current cigarette or tobacco packet when asked two weeks

Table 1 Comparison between type of cigarette on questionnaire and packet

\begin{tabular}{|c|c|c|c|c|c|}
\hline \multirow{2}{*}{$\begin{array}{l}\text { Type of cigarette on } \\
\text { questionnaire }\end{array}$} & \multicolumn{5}{|c|}{ Type of cigarette on packet } \\
\hline & Manufactured filter & Manufactured plain & Hand rolled & Missing packet & Total \\
\hline $\begin{array}{l}\text { Manufactured filter } \\
\text { Manufactured plain } \\
\text { Hand rolled } \\
\text { Missing data } \\
\text { Total }\end{array}$ & $\begin{array}{r}135 \\
2 \\
2 \\
1 \\
140\end{array}$ & $\begin{array}{r}1 \\
11 \\
0 \\
1 \\
13\end{array}$ & $\begin{array}{r}2 \\
0 \\
64 \\
1 \\
67\end{array}$ & $\begin{array}{r}13 \\
1 \\
6 \\
3 \\
23\end{array}$ & $\begin{array}{r}151 \\
14 \\
72 \\
6 \\
243\end{array}$ \\
\hline
\end{tabular}


Table 2 Comparison between tar groups on questionnaire and cigarette or tobacco packet

\begin{tabular}{|c|c|c|c|c|c|c|}
\hline \multirow[t]{2}{*}{ Tar group on questionnaire } & \multicolumn{6}{|c|}{ Tar level on cigarette or tobacco packet } \\
\hline & "Middle" & "Low middle" & "Low" & $\begin{array}{l}\text { Hand rolled } \\
\text { ("unknown") }\end{array}$ & Missing packet & Total \\
\hline $\begin{array}{l}\text { "Middle high" } \\
\text { "Middle" } \\
\text { "Low middle"" } \\
\text { "Low" } \\
\text { "Unknown" } \\
\text { Total }\end{array}$ & $\begin{array}{r}7 \\
50 \\
6 \\
1 \\
2 \\
66\end{array}$ & $\begin{array}{r}3 \\
12 \\
22 \\
2 \\
1 \\
40\end{array}$ & $\begin{array}{r}0 \\
3 \\
3 \\
41 \\
0 \\
47\end{array}$ & $\begin{array}{r}1 \\
10 \\
7 \\
2 \\
47 \\
67\end{array}$ & $\begin{array}{l}0 \\
0 \\
2 \\
1 \\
1 \\
4\end{array}$ & $\begin{array}{r}11 \\
75 \\
40 \\
47 \\
51 \\
224\end{array}$ \\
\hline
\end{tabular}

Overall agreement $73 \%(160 / 220)$

after completing the questionnaire.

Table 1 shows that there was close agreement between the type of cigarette named in the questionnaire and on the packet-that is, for 210 out of 217 subjects from whom full information was obtained. Table 2 compares the tar group specified in the questionnaire with that on the cigarette or tobacco packet. Only 22 out of $40(55 \%)$ smokers of "low middle" tar cigarettes were correctly identified in the questionnaire. Twenty out of $67(30 \%)$ smokers of hand rolled tobacco erroneously ascribed a tar level to their cigarette.

The overall agreement between the brand name in the questionnaire and that on the cigarette or tobacco packet was $74 \%$. None of the smokers who wrote on the questionnaire a brand different from that of the submitted packet had mentioned more than one brand on the questionnaire or had returned more than one packet. All of the men when contacted after returning a packet claimed that the packet returned was that of their usual cigarette and all but one stated on the questionnaire that they had been smoking the questionnaire brand for less than a year. There was therefore no evidence that the disagreement between questionnaire and packet over brand name was due to smoker's failure to mention their usual brand on the questionnaire or to forward a packet of their usual cigarette type. Most of the discrepancies arose because the usual brand was inadequately described on the questionnaire-for example, Embassy Regal KS was referred to as Embassy KS.
Tables 3 and 4 compare the tar group on the questionnaire and on the packet returned two weeks later for smokers whose questionnaire and packet agreed and disagreed respectively over brand name. Smokers whose questionnaires and returned packets disagreed on brand name were found to be discrepant on tar group in only $46 \%$ of cases.

Two hundred and sixteen of the men who smoked cigarettes at the start of the Heart Disease Prevention Project admitted that they could not recall the brand of cigarette smoked at that time. A further 43 wrongly claimed not to have been smoking at the start of the project. The overall agreement between the brand of cigarette or tobacco which the remaining 170 smokers and ex-smokers thought they were smoking at the start of the project and the brand that was actually recorded at that time was $49 \%$. The agreement was greater for hand rolled cigarettes-24/34 $(71 \%)$ than for manufactured cigarettes- $60 / 136(44 \%)$.

\section{Discussion}

Whether a person smokes a plain or a filter cigarette has often been used in epidemiological studies to allocate smokers to a higher or lower tar group respectively for the purpose of analysis. ${ }^{12910}$ This study suggests that the information about type of cigarette smoked given on a self administered questionnaire is fairly accurate for this purpose. Although only two out of the $13(15 \%)$ smokers of plain manufactured cigarettes were incorrectly identified, the

Table 3 Comparison between tar groups on questionnaire and cigarette or tobacco packet when the two agreed on brand name

\begin{tabular}{|c|c|c|c|c|c|c|}
\hline \multirow[t]{2}{*}{ Tar group on questionnaire } & \multicolumn{6}{|c|}{ Tar level on cigarette or tobacco packet } \\
\hline & "Middle" & "Low middle" & "Low" & $\begin{array}{l}\text { Hand rolled } \\
\text { ("unknown") }\end{array}$ & Missing packet & Total \\
\hline $\begin{array}{l}\text { "Middle high" } \\
\text { "Middle" } \\
\text { "Low middle" } \\
\text { "Low" } \\
\text { "Unknown" } \\
\text { Total }\end{array}$ & $\begin{array}{r}5 \\
44 \\
2 \\
0 \\
2 \\
53\end{array}$ & $\begin{array}{r}1 \\
6 \\
17 \\
1 \\
1 \\
26\end{array}$ & $\begin{array}{r}0 \\
0 \\
1 \\
31 \\
0 \\
32\end{array}$ & $\begin{array}{r}0 \\
8 \\
5 \\
2 \\
38 \\
53\end{array}$ & $\begin{array}{l}0 \\
0 \\
1 \\
0 \\
0 \\
1\end{array}$ & $\begin{array}{r}6 \\
58 \\
26 \\
34 \\
41 \\
165\end{array}$ \\
\hline
\end{tabular}

Overall agreement $79 \%(130 / 164)$ 
Table 4 Comparison between tar groups on questionnaire and cigarette or tobacco packet when the two disagreed on brand name

\begin{tabular}{|c|c|c|c|c|c|c|}
\hline \multirow[t]{2}{*}{ Tar group on questionnaire } & \multicolumn{6}{|c|}{ Tar level on cigarette or tobacco packet } \\
\hline & "Middle" & "Low middle" & "Low" & $\begin{array}{l}\text { Hand rolled } \\
\text { ("unknown") }\end{array}$ & Missing packet & Total \\
\hline $\begin{array}{l}\text { "Middle high" } \\
\text { "Middle" } \\
\text { "Low middle" } \\
\text { "Low" } \\
\text { "Unknown" } \\
\text { Total }\end{array}$ & $\begin{array}{r}2 \\
6 \\
4 \\
1 \\
0 \\
13\end{array}$ & $\begin{array}{r}2 \\
6 \\
5 \\
1 \\
0 \\
14\end{array}$ & $\begin{array}{r}0 \\
3 \\
2 \\
10 \\
0 \\
15\end{array}$ & $\begin{array}{r}1 \\
2 \\
2 \\
0 \\
9 \\
14\end{array}$ & $\begin{array}{l}0 \\
0 \\
1 \\
1 \\
1 \\
3\end{array}$ & $\begin{array}{r}5 \\
17 \\
14 \\
13 \\
10 \\
59\end{array}$ \\
\hline
\end{tabular}

Overall agreement $54 \%(30 / 56)$

numbers are small and the confidence limits on the percentage disagreement wide. In the early 1970 s smokers of plain manufactured cigarette smokers formed a substantial proportion of all male smokers of manufactured cigarettes, and our findings cannot confirm the accuracy of studies that collected information about type of cigarette smoked at that time by means of self or interviewer administered questionnaires, rather than from the cigarette packet itself.

None of the prospective, cross sectional, or casecontrol studies that have compared the morbidity and mortality of smokers of cigarettes of different tar yields have so far used the tar group, indicated on the cigarette packet, as a basis on which to allocate smokers to higher or lower tar smoking groups for analysis. If this were the case and such information were collected by self administered questionnaire, this study suggests that, whereas nearly all of the smokers allocated to a "low" tar group would actually smoke "low" tar cigarettes, as many as 15 out of the $75(20 \%)$ smokers allocated to the "middle" tar cigarette group would have been more correctly assigned to the "low" or "low middle" tar group (table 2). This erroneous allocation of "low" tar smokers to a higher group would be expected to increase the chances of missing a significant difference in morbidity or mortality between the groups.

Nevertheless the size of the quantitative error indicated by table 2 might still allow a comparison between people who report smoking different brands to be useful. Given that 19,13 , and $8 \mathrm{mg}$ are the average tar levels of the three tar groups "middle," "low middle," "low" on the cigarette packet, then for the 150 people who supplied valid data on the smoking of manufactured cigarettes on both, the means for the questionnaire groups would be: middle high = $17.2 \mathrm{mg}((7 \times 19+3 \times 13) / 10) ;$ middle $=17.4 \mathrm{mg}$; low middle $=13.7 \mathrm{mg}$; low $=8.5 \mathrm{mg}$. Thus, apart from the middle high group, there still seems to be a substantial difference in tar yields between people who report smoking different brands.

Most studies have used the exact tar yield of the

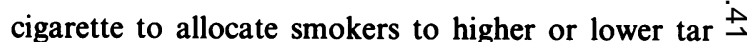
smoking groups for analysis. The exact tar yields $\dot{\omega}$ have usually been deduced from the brand name of $\stackrel{N}{\circ}$ the cigarette currently smoked as given on a self ${ }^{\mathcal{L}}$ administered or interviewer administered question- $\supset$ naire. $^{3591215}$ Very few of the studies make any refer- $\vec{z}$ ence to the amount of information that needs to be

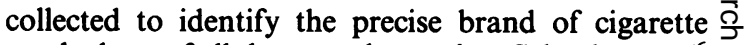
smoked out of all those on the market. Schenker et $a l^{6} \overrightarrow{.}$ included specifications of length, filter, packet type (soft packet or box), and flavour (regular or menthol) under cigarette brand, and our results confirm that this sort of detail is necessary. We recommend, however, that smokers should be asked to return an empty packet of the cigarette usually smoked with a self administered questionnaire, and we found from a $尺$ postal survey of 20000 households that $90 \%$ of $\overrightarrow{\vec{B}}$ smokers were willing to do this. ${ }^{20}$

Most cross sectional and some case-control studies have compared smokers of cigarettes of different tar: yields according to their current smoking habits only. $\vec{F}$ A recent trend is for studies to inquire about past as well as present cigarette brands smoked. In the $\stackrel{x}{x}$ case-control study carried out by Lubin et $a^{16} \frac{\mathrm{O}}{3}$ respondents were expected to recall up to the last four cigarette brands smoked but the authors were not $\delta$ able to test the validity of the recall. In our study only about $49 \%$ of the brands that smokers claimed they 음 smoked 12 years ago were confirmed by records made $D$ at that time. The Heart Disease Prevention Project's questionnaire used to obtain data on the brand of $N$ cigarette smoked in 1971-3 asked about the brand of ${ }^{\circ}$ cigarette or hand rolling tobacco usually smoked. $)$ Thus subjects were allowed to give only one answer $\underset{\omega}{\omega}$ regarding the brand smoked. An appreciable proportion of male cigarette smokers used both manu- 0 factured and hand rolled cigarettes. Possibly part of $\stackrel{\odot}{\mathbb{D}}$ the $51 \%$ discrepancy found between the brand $\stackrel{\odot}{+}$ thought to be smoked at the start of the project and 0 the brand recorded at the time arose because the men $\stackrel{\vec{P}}{\mathrm{~T}}$ were allowed to give only one answer on the HDPP $\cong$ questionnaire. Only 12 out of the 84 discrepancies $\stackrel{\mathbb{Q}}{\Omega}$ between the two questionnaires, however, arose $\overline{0}$ 
because subjects said that they smoked a manufactured cigarette at the start of the project whereas a hand rolling tobacco was recorded at the time, or vice versa. Allowing for the requirement to indicate only a manufactured or a hand rolled cigarette on the HDPP questionnaire still produces a discrepancy of $42 \%$ over brand smoked in 1971-3 between the two questionnaires. This suggests that follow up studies of populations on which brand of cigarette smoked was incidentally recorded during a survey some years previously might be more valid than studies relying on recall of the brand of cigarette smoked.

We thank Dr RF Heller, assistant director HDPP, for allowing us to resurvey men in that study, Professor Holland and Mr Peter Lee for their advice and criticism and Mrs L Clarke for word processing the manuscript. The study was funded by the Tobacco Products Research Trust.

\section{References}

1 Wynder EL, Mabuchi K, Beattie EJ. The epidemiology of lung cancer: recent trends. $J A M A$ 1970;213:2221-8.

2 Rimington J. Phlegm and filters. $\mathrm{Br}$ Med J 1972;ii:262-4.

3 Higenbottam T, Clark TJH, Shipley MJ, Rose G. Lung function and symptoms of cigarette smokers related to tar yield and number of cigarettes smoked. Lancet 1980;i:409-12.

4 Beck GJ, Doyle CA, Schachter EN. Smoking and lung function. Am Rev Respir Dis 1981;123:149-55.

5 Higenbottam T, Shipley MJ, Rose G. Cigarettes, lung cancer, and coronary heart disease: the effects of inhalation and tar yield. J Epidemiol Commun Health 1982;36:113-7.

6 Schenker MB, Samet JM, Speizer FE. Effect of cigarette tar content and smoking habits on respiratory symptoms in women. Am Rev Respir Dis 1982;125:684-90.

7 Comstock GW, Brownlow WJ, Stone RW, Sartwell PE. Cigarette smoking and changes in respiratory findings. Arch Environ Health 1970;21:50-7.

8 Hammond EC, Garfinkel L, Seidman H, Lew EA. Tar and nicotine content of cigarette smoke in relation to death rates. Environ Res 1976;12:263-74.

9 Hawthorne VM, Fry JS. Smoking and health: the association between smoking behaviour, total mortality and cardiorespiratory disease in west central Scotland. $J$ Epidemiol Commun Health 1978;32:260-6.

10 Rimington J. The effect of filters on the incidence of lung cancer in cigarette smokers. Environ Res 1981;24:162-6.

11 Castelli WP, Garrison RJ, Dawber TR, et al. The filter cigarette and coronary heart disease: the Framingham study. Lancet 1981;ii:109-13.
12 Sparrow D, Stefos T, Bosse R, Weiss ST. The relationship of tar content to decline in pulmonary function in cigarette smokers. Am Rev Respir Dis 1983; 127:56-8.

13 Wynder EL, Stellman JD. Impact of long term filter cigarette usage on lung and larynx cancer risk: a casecontrol study. J Natl Cancer Inst 1979;62:471-7.

14 Kaufman DW, Helmrich SP, Rosenberg L, et al. Nicotine and carbon monoxide content of cigarette smoke and the risk of myocardial infarction in young men. $N$ Engl J Med 1983;308:409-13.

15 Vutuc C, Kunze M. Tar yields of cigarette and male lung cancer risk. J Natl Cancer Inst 1983;71:435-7.

16 Lubin JH, Blot WJ, Berrino F, et al. Patterns of lung cancer risk according to type of cigarette smoked. Int J Cancer 1984;33:569-76.

17 Hoinville GW, Biggs HW. Establishing smoking habits in retrospect. Statistician 1967;16:23-43.

18 Fletcher C, Peto R, Tinker C, Speizer FE. The natural history of chronic bronchitis and emphysema. Oxford: Oxford University Press, 1976.

19 Rose G, Heller RF, Tunstall Pedoe H, Christie G. Heart disease prevention project: a randomised controlled trial in industry. $\mathrm{Br}$ Med J 1980;i:747-51.

20 Peach H, Ellard GA, Hayward D, Morris RW, Shah D. A randomised controlled trial of low versus middle tar cigarettes on respiratory symptoms-a feasibility study. In: Tobacco: a major issue. (Proceedings of International Meeting on Cancer Control and Prevention, Moscow, 1985.) Lyon: IARC Scientific Publications (in press).

$\begin{array}{llll}\text { Appendix } & & & \\ & & & \\ \text { Cigarettes not specified } & 00 & \text { Sterling } & 19 \\ \text { Cadet tipped } & 01 & \text { Woodbines } & 20 \\ \text { Capstan } & 02 & \text { Benson and Hedges } \$ & 21 \\ \text { Consulates } & 03 & \text { Benson and Hedges King Size } & 22 \\ \text { Embassy } & 04 & \text { Other King Size } & \\ \text { Gold Leaf } & 05 & \text { Tipped } & 47 \\ \text { Guards } & 06 & \text { Other tipped } & 48 \\ \text { Kensitas } & 07 & \text { Other ordinary } & 49 \\ \text { Mayfair } & 08 & \text { Tobacco (not specified) } & 50 \\ \text { Nelson } & 09 & \text { Boars Head } & 51 \\ \text { Peter Stuyvesant } & 10 & \text { Golden Virginia } & 52 \\ \text { Players* } & 11 & \text { Old Holborn } & 53 \\ \text { Players Weights } & 12 & \text { Players Medium } & 54 \\ \text { Players No 6 } & 13 & \text { St Julian } & 55 \\ \text { Piccadilly } & 14 & \text { Special Nosegay } & 56 \\ \text { Rothmans } † & 15 & \text { Sun Valley } & 57 \\ \text { Rothmans King Size } & 16 & \text { Three Castles } & 58 \\ \text { Senior Servicet } & 17 & \text { Nut Brown } & 59 \\ \text { Senior Service Filter } & 18 & \text { Others } & 60\end{array}$

*Except 12, 13, 17, 18, 20.

†Except 16.

†Except 18.

§xcept 22. 